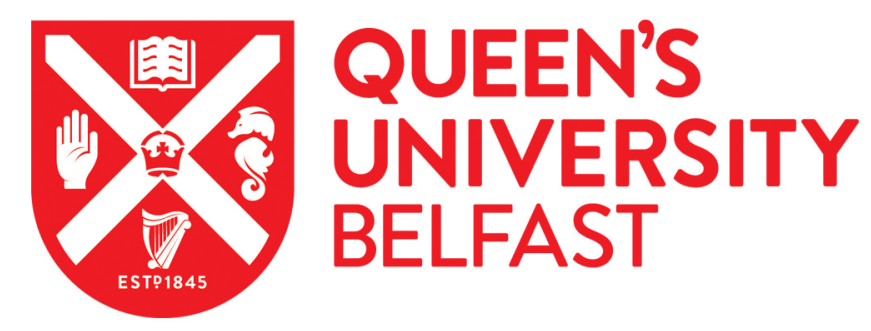

\title{
Assessing serum metabolite profiles as predictors for feed efficiency in broiler chickens reared at geographically distant locations
}

Metzler-Zebeli, B., Magowan, E., Hollman, M., Ball, E., Molnar, A., Lawlor, P. G., Hawken, R., O'Connell, N., \& Zebeli, Q. (2017). Assessing serum metabolite profiles as predictors for feed efficiency in broiler chickens reared at geographically distant locations. BRITISH POULTRY SCIENCE, 1-10.

https://doi.org/10.1080/00071668.2017.1362688

Published in:

BRITISH POULTRY SCIENCE

Document Version:

Peer reviewed version

Queen's University Belfast - Research Portal:

Link to publication record in Queen's University Belfast Research Portal

Publisher rights

(c) 2017 Taylor and Francis

This work is made available online in accordance with the publisher's policies. Please refer to any applicable terms of use of the publisher.

\section{General rights}

Copyright for the publications made accessible via the Queen's University Belfast Research Portal is retained by the author(s) and / or other copyright owners and it is a condition of accessing these publications that users recognise and abide by the legal requirements associated with these rights.

Take down policy

The Research Portal is Queen's institutional repository that provides access to Queen's research output. Every effort has been made to ensure that content in the Research Portal does not infringe any person's rights, or applicable UK laws. If you discover content in the Research Portal that you believe breaches copyright or violates any law, please contact openaccess@qub.ac.uk. 
1 Running head: Serum predictors for RFI in chickens

2

3

4

5

6

7

8

9

\section{Assessing serum metabolite profiles as predictors for feed efficiency in} broiler chickens reared at geographically distant locations

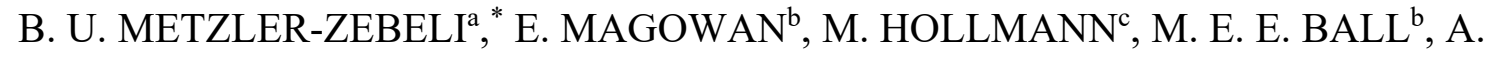
MOLNÁR ${ }^{\mathrm{b}}$, P. G. LAWLOR ${ }^{\mathrm{d}}{ }^{\#}$ R. J. HAWKEN ${ }^{\mathrm{e}}, \mathrm{N}$. E. O’CONNELL ${ }^{\mathrm{f}}$, and Q. ZEBELI ${ }^{\mathrm{b}}$

${ }^{a}$ University Clinic for Swine, Department for Farm Animals and Veterinary Public Health, University of Veterinary Medicine, Veterinaerplatz 1, 1210 Vienna, Austria

${ }^{b}$ Agri-Food and Biosciences Institute, Agriculture Branch, Large Park, Co. Down BT26 6DR, Hillsborough, Northern Ireland, United Kingdom;

'Institute of Animal Nutrition and Functional Plant Compounds, Department for Farm

Animals and Veterinary Public Health, University of Veterinary Medicine, Vienna,

Veterinaerplatz 1, 1210 Vienna, Austria;

${ }^{d}$ Teagasc Pig Development Department, Animal \& Grassland Research \& Innovation Centre, Moorepark, Fermoy, Co. Cork, Ireland;

${ }^{e}$ Cobb-Vantress Inc., 4703 U.S. Highway 412 East, Siloam Springs, AR 72761-1030;

IInstitute for Global Food Security, School of Biological Sciences, Queen's University Belfast, Belfast, BT9 7BL,UK.

Correspondence to: Barbara U. Metzler-Zebeli, University Clinic for Swine, Department for Farm Animals and Veterinary Public Health, University of Veterinary Medicine Vienna, Veterinaerplatz 1, 1210 Vienna, Austria, E-mail: barbara.metzler@vetmeduni.ac.at 


\section{Abstract}

1. Various physiological mechanisms contribute to feed efficiency (FE) in chickens. Blood metabolite profiles may correlate to the animal's FE, but have rarely been evaluated in chickens. The objective of this study was to investigate differences in growth performance, serum intermediary metabolites, acute-phase-proteins and white blood cells in low, medium and high residual feed intake (RFI) chickens. It was also assessed if the environment affects the FE and FE-related performance and serum profiles of chickens.

2. Individual BW and feed intake (FI) were recorded from d 7 of life. At 5 weeks of age, female and male chickens (Cobb 500) were selected according to their RFI (L1: Austria; L2: UK; $n=9 /$ RFI group, sex and location) and blood was collected.

3. Chickens at L1 had similar FI but a $15 \%$-higher $(P<0.001)$ BW gain compared to chickens at L2. The RFI values of female chickens were -231, 8 and $215 \mathrm{~g}$ and those of male chickens 197, 0 and $267 \mathrm{~g}$ for low, medium and high RFI, respectively $(P<0.001)$.

4. Location affected serum glucose, urea, cholesterol, NEFA and ovotransferrin in females, and serum glucose and triglycerides in male chickens $(P<0.05)$. Serum uric acid and NEFA linearly increased from low to high RFI in females, whereas in males cholesterol showed the same linear response from low to high RFI $(P<0.05)$. Serum alpha-1-acid glycoprotein and blood heterophil-to-lymphocyte ratio linearly increased by 35 and 68\%, respectively, from low to high RFI but only in male chickens at L1 $(P<0.05)$.

5. Regression analysis showed positive relationships between RFI and serum uric acid $\left(R^{2}=\right.$ $0.49 ; P<0.001)$ and cholesterol $\left(R^{2}=0.13 ; P<0.001\right)$.

6. We conclude that RFI-related variation in serum metabolites of chickens was largely similar for the two environments and that serum metabolite patterns could be used to predict RFI in chickens. 
50 Key words: acute phase response, broilers, feed-efficiency predictor, residual feed intake, 51 serum metabolites 


\section{Introduction}

Improving feed efficiency (FE) is a continuing goal since feed is the major cost in chicken production. Improved FE is often associated with reduced feed intake (FI) (Bottje and Carstens, 2009). As it is a heritable trait and is independent of production traits, the residual feed intake (RFI) has become the metric of choice for studying physiological mechanisms underlying variation in FE of chickens and other livestock species (Herd and Arthur, 2009; Berry and Crowley, 2012). Generally, a chicken population from a commercial breed shows considerable variation in RFI (van Eerden et al., 2004). As knowledge about RFI related physiological mechanisms in poultry and other livestock species advances, the biological basis of inter-animal variations associated with FE becomes clearer (Bottje and Carstens, 2009; Aggrey et al., 2014; Lee et al. 2015; Mignon-Grasteau et al., 2015; Zhuo et al., 2015). In beef cattle and pigs some plasma metabolites and hormones correlated with animal's RFI and have been discussed as RFI predictors (Kelly et al., 2010; Le Naou et al., 2012;

Montagne et al., 2014). Some evidence for RFI-associated differences in serum intermediary metabolites also exists for cockerels (Gabbarou et al., 1997; Swennen et al., 2007); however, due to the short production cycle, these have not been satisfactorily studied in meat-type chickens. In general, peripheral blood is more easily accessible than other body tissues and can provide useful information to identify the main biological processes which are modulated by genetic selection or by feeding strategies (Jegou et al., 2016).

The question whether meat-type chickens of diverging RFI respond differently to stressors which may affect growth performance (Zulkifli et al., 2014) has also not been completely answered. In pullets, for instance, differences in RFI-related stress responses are small (van Eerden et al., 2004). Overall, concentrations of blood corticosterone, acute-phase-proteins (APP) and heterophil-to-lymphocyte ratio (H-to-L) correlate in poultry (Gross and Siegel, 1983). Hence, APPs and the H-to-L ratio are commonly used as indices of stress in chickens 
(Zulkifli et al., 2000, 2014) and may help understanding RFI-related stress responses in broiler chickens.

In most studies, RFI was derived from one contemporary population of chickens (Bottje and Carstens, 2009), whereas information regarding the impact of the rearing environment on RFI-related variation is scarce. In considering that substantial batch-to-batch variation has been reported for the chicken gut microbiota under controlled conditions at one experimental setting (Stanley et al., 2013, 2016; Ludvigsen et al., 2016), it is feasible that the environment may modify RFI-related physiological responses. This is an important issue since any predictors or biomarkers of FE must be applicable across multiple environments and the result will influence the approaches used to measure and manipulate the underlying physiological mechanisms to improve FE gain.

We therefore hypothesized that, despite being raised in different environments, chickens of equal RFI would be characterized by similar RFI-related profiles for performance and serum parameters. The first objective of this study were to investigate differences in growth performance, FE, serum intermediary metabolites, acute-phase-proteins and white blood cells in low, medium and high residual feed intake (RFI) chickens. The second objective was to assess if the environment in which chickens were raised affect chicken's FE and FE-related performance and serum profiles.

\section{Materials and Methods}

\section{Experimental design and chickens}

Two chicken experiments using common protocols comprising the experimental setup, diet formulation, data and sample collection were conducted at the Institute of Animal Nutrition and Functional Plant Compounds [University of Veterinary Medicine Vienna, Austria; location 1 (L1)] and at the Agriculture Branch of Agri-Food and Biosciences Institute [Hillsborough, Northern Ireland, United Kingdom; location 2 (L2)] using a completely 
randomized study design. At both locations three replicate batches were performed using dayold mixed-sex Cobb 500FF chicks, resulting in a total population of 78 females and 79 males at L1 and in a total population of 96 females and 96 males at L2. Within each replicate batch, equal numbers of females and males, except for batch 2 with one more male at L1, were used. Due to the geographic distance, chickens came from different commercial hatcheries. The three chicken batches at each location were run in parallel. All animal experimentation procedures were approved by the institutional ethics committee at the University of Veterinary Medicine Vienna and the Austrian national authority according to paragraph 26 of Law for Animal Experiments, Tierversuchsgesetz 2012 - TVG 2012 (GZ 68.205/0131— II/3b/2013). At Agri-Food and Biosciences Institute the animal procedures were conducted under the project licence number PPL 2781 obtained from the Department of Health, Social Services and Public Safety (DHSSPS) which adhere to the Animals (Scientific Procedures) Act 1986.

At hatch, chicks were sexed and transported to L1 and L2 within the first day of life, where chicks were weighed and group-housed. From d 7 of life, chickens were separated and individually housed in cages until the end of the experimental period. The cage floors were made of wire mesh $(10 \mathrm{~mm} \times 10 \mathrm{~mm})$ and padded with rubber tubing. The chickens received a light-to-dark ratio of $23: 1 \mathrm{~h}$ on the day of arrival which was gradually decreased to $18: 6 \mathrm{~h}$ on d 6 of life and was maintained throughout the experimental period. The temperature was maintained at $33^{\circ} \mathrm{C}$ for the first 5 days after which it was gradually decreased to a temperature of $21^{\circ} \mathrm{C}$ on d 21 of life. Each cage was equipped with one manual feeder and one drinker and feed and demineralized water were freely available.

\section{Diets and Data Collection}

Chickens were fed starter, grower and finisher diets based on corn and soybean meal (Table 1) from d 1 to $10, \mathrm{~d} 11$ to 21 , and d 22 to 42 of life, respectively. Diets did not contain anti- 
microbial growth promoters or coccidiostats. Starter, grower and finisher diets were mixed according to the same diet formulation at each location. At each location, starter, grower and finisher diets for the replicate batches came from the same batch of commercially prepared crumbles (starter diet) and pellets ( $3 \mathrm{~mm}$; grower and finisher diets) and were stored in cool $\left(<15^{\circ} \mathrm{C}\right)$ and dry conditions for a duration of no longer than 6 months. Feed intake (FI) was determined weekly. Feed leftovers and spills were collected before recording feed intake on d $14,21,28,35,36$ and 38 of life. Once a week (upon arrival, $d 7,14,21,28$ and 35) and on the selection day, BW of all chickens were recorded at both locations.

\section{Selection procedure and calculation of FE}

Due to the fact that chickens at L1 grew faster than chickens at L2, selection of chickens at L1 took place two days earlier on d 36 of life in order to achieve approximately similar BW at sacrifice and hence to minimize the effect of BW and body composition on parameters of interest. Chickens at L2 were weighed and ranked according to their RFI value on d 38 of life. The RFI was calculated for each chicken for the test interval between $\mathrm{d} 7$ and d 36 of life at L1 and between d 7 and d 38 of life at L2, respectively. Data for net total FI (TFI), metabolic mid-test metabolic weight and total BW gain (TBWG) were used to estimate RFI and residual BW gain (RBG) values as the residuals over the test interval with a nonlinear mixed model in SAS (SAS Stat Inc., version 9.2; Cary; NC) as described in Metzler-Zebeli et al. (2016):

\section{The MMW was calculated as:}

$\mathrm{MMW}=[(\mathrm{BW} \text { at } \mathrm{d} 7 \text { of life }(\mathrm{g})+\mathrm{BW} \text { at d } 35 \text { of life }(\mathrm{g})) / 2]^{0.75}$.

The RFI and RBG were calculated as:

$$
\operatorname{RFI}(\mathrm{g})=\mathrm{TFI}-\left(\mathrm{a}_{1}+\mathrm{b}_{1} \times \mathrm{MMW}+\mathrm{b}_{2} \times \mathrm{TBWG}\right),
$$

where $a_{1}$ is the intercept and $b_{1}$ and $b_{2}$ are partial regression coefficients of MMW and TBWG on TFI, respectively. In addition, RBG, residual intake over gain (RIG) and feed conversion ratio (FCR) for the test interval were calculated for the selected chickens: 


$$
\text { RBG }(\mathrm{g})=\text { TBWG }-\left(\mathrm{a}_{2}+\mathrm{b}_{3} \times \mathrm{MMW}+\mathrm{b}_{4} \times \mathrm{TFI}\right),
$$

where $a_{2}$ is the intercept and $b_{3}$ and $b_{4}$ are partial regression coefficients of MMW and TFI on TBWG, respectively.

The RIG was calculated as:

$$
\operatorname{RIG}(\mathrm{g})=\mathrm{RBG}(\mathrm{g})-\mathrm{RFI}(\mathrm{g}) \text {. }
$$

The FCR was calculated as:

$$
\text { FCR }(\mathrm{g} / \mathrm{g})=\mathrm{TFI}(\mathrm{g}) / \mathrm{TBWG}(\mathrm{g})
$$

In each replicate, batch and location it was aimed to select the three chickens with the lowest RFI (Low RFI), the three chickens with the highest RFI (High RFI), and the three chickens with the medium RFI (Medium RFI; a RFI value close to zero), separately for female and male chickens. Finally, at location 1, each RFI group was represented by 9 females and 9 males. At location 2, 6 low RFI, 11 medium RFI and 6 high RFI female chickens and 10 low RFI, 9 medium RFI and 9 high RFI male chickens were selected. Only the data of the selected chickens at both locations were used for the comparison of FI, growth performance and FE. Moreover, blood samples were only collected from the selected chickens. The remaining chickens were removed from the experiment. TFI and TBWG were compared for the test interval from $\mathrm{d} 7$ to 36 of life across locations.

\section{Blood sampling}

Body weight of selected chickens was recorded before chickens were humanely killed for blood sampling from d 37 to 42 of life. At L1, selected chickens were euthanized with an overdose of sodium pentobarbital (450 mg/kg, Release, WTD-Wirtschaftsgenossenschaft Deutscher Tierärzte, Garbsen, Germany) by i.v. injection into the caudal tibial vein from d 37 of life with three to six chickens per day, whereas at L2 selected chickens were sacrificed on d 41 and 42 of life. Immediately thereafter, blood from the vena jugularis at L1 and the heart at L2 was collected into serum collection tubes (Sarstedt, Nürnbrecht, Germany) and placed on 
ice until centrifugation $\left(1811 \times \mathrm{g}\right.$ for $10 \mathrm{~min}$ and $1500 \times \mathrm{g}$ at $4^{\circ} \mathrm{C}$ for $10 \mathrm{~min}$ at $\mathrm{L} 1$ and $\mathrm{L} 2$, respectively; Eppendorf Centrifuge 5810 R, Eppendorf, Hamburg, Germany), and stored at $20^{\circ} \mathrm{C}$ until analysis. At L1, $1 \mathrm{~mL}$ blood was additionally collected in tubes containing EDTA as anticoagulant (Sarstedt, Nürnbrecht, Germany) from which blood smears were prepared on glass slides ( $n=4 /$ chicken) to count white blood cells. The intestinal mucosa was checked for Eimeria-related lesions at the necropsy which could not be detected.

\section{Chemical analysis and calculations}

Proximate nutrient analysis of diet samples was performed according to standard protocols (Naumann and Basler, 2012). Dry matter was determined after oven-drying for $4 \mathrm{~h}$ at $103^{\circ} \mathrm{C}$ (method 3.1), crude ash by overnight incineration at $550^{\circ} \mathrm{C}$ (method 8.1 ), and $\mathrm{CP}$ (nitrogen $\times$ 6.25) by the Kjeldahl method (method 4.1.1; Naumann and Basler, 2012). Diet samples were further analyzed for EE (method 5.1.1B), CF (method 6.1.1), total starch (method 7.2.1), sugar (method 7.1.1), calcium (method 10.3.2) and phosphorus (method 10.6.1; Naumann and Basler, 2012).

\section{Blood leukocyte counts, serum metabolites, and acute-phase proteins}

Blood smears were stained using the May-Grünwald-Giemsa stain (Hemacolor Rapid staining of blood smear kit; Merck KGaA, Darmstadt, Germany). A total of 100 leukocytes, including granular (heterophils, eosinophils, and basophils) and nongranular (lymphocytes and monocytes), were counted per slide using light microscopy (Leitz Orthoplan, Leitz, Wetzlar, Germany) at 100-times magnification, and the H-to-L ratio was calculated (Gross and Siegel, 1983). Serum glucose, uric acid, triglycerides, cholesterol and NEFA were determined by standard enzymatic colorimetric analysis using an autoanalyzer for clinical chemistry (Cobas 6000/c501; Roche Diagnostics GmbH, Vienna, Austria). Chicken specific commercial ELISA kits were used to determine the APPs ovotransferrin (OVT; Cusabio, Wuhan, China) and 
alpha-1-acid glycoprotein (AGP; Genway Biotech Inc., San Diego, CA, US) in serum according to the manufacturers' instructions. Samples were diluted 2 to 5-fold for both assays depending on the individual sample concentration. The intra- and interassay variability for the OVT and AGP kits were less than 10\%, respectively, and the detection limit was $0.039 \mathrm{ng} / \mathrm{ml}$ and $3.125 \mathrm{ng} / \mathrm{ml}$. All serum parameters were analyzed together at L1.

\section{Statistical analysis}

Feed efficiency, FI, growth performance and serum parameters from the selected low, medium and high RFI chickens (location 1: $n=9$ low, medium and high RFI female and male chickens; location 2: $n=6$ low RFI, $n=11$ medium RFI and $n=8$ high RFI females, and $n=$ 10 low RFI, $n=9$ medium RFI and $n=9$ high RFI males) were first analysed for normality using Shapiro-Wilk test with the PROC UNIVARIATE in SAS. The Cook's distance (Cook's D) test was used to determine any influential observation on the model. Parameters of individual RFI, performance, and serum metabolites, APPs and white blood cells were analysed by ANOVA using the PROC MIXED in SAS. Two models were run. The first accounted for the fixed effects of sex, batch, location and RFI. Because chickens were sacrificed at different days of life and in order to consider that chickens were consecutively sampled, the first model included the random effect of chicken nested within day of life and chicken order at sacrifice. The effects of bird age and BW at 7 days of life were also separately tested as covariates in the model. As both covariate effects showed no significant influence on any response variable evaluated, these covariates were removed from the final model and not accounted for in the further analyses. However, sex and batch as fixed effects were found to be significant for many parameters. Therefore, data of female and male chickens were analysed separately using a second model which was fitted to take into account the fixed effects of RFI and location and their two-way-interaction. The random effect considered the chicken nested within batch, day of life and chicken order at sacrifice. Since 
white blood cell counts were only determined at L1, only the fixed effect of RFI was considered. Moreover, in the second model, orthogonal polynomial contrast statement was used to evaluate linear relationships. Degrees of freedom were approximated by the method of Kenward-Roger. Least squares means were computed and significance declared at $P \leq 0.05$. A trend was considered at $0.05<P \leq 0.10$.

In order to investigate whether sex-independent relationships between chicken's individual RFI and serum metabolites existed linear discriminate analysis (LDA) and regression analysis were applied. The LDA was performed using JMP10 software (SAS Stat Inc.) with serum metabolites (glucose, urea, cholesterol, triglycerides and NEFA) as covariates and RFI group as the categorical variable. The LDA results were visualised using the first 2 principal components of the scores plot to identify characteristic trends or grouping among chickens of diverging RFI. Moreover, regression analysis (PROC REG of SAS) was used to establish and quantify the relationships between individual serum metabolites, serum APPs and blood H-to-L ratio and chickens' individual RFI values, irrespective of sex and location. For this, mixed modelling (PROC MIXED of SAS) of each serum metabolite was performed including the fixed effects RFI, sex and location. The slope and intercept by RFI, sex and location were included as random effects and the variance component structure was used as variance-covariance matrix. Significant relationships $(P<0.05)$ are shown in Fig. 1.

\section{Results}

\section{Chicken performance and feed efficiency}

Sex did not affect BW on d 7 of life, whereas male chickens weighed approximately $300 \mathrm{~g}$ more on $\mathrm{d} 36$ of life than females $(P<0.001$; Table 1 and 2). Similarly, TFI and TBWG were higher $(P<0.001)$ in males compared to females. Location affected BW on d 7 and 36 of life. While female and male chickens weighed about $10 \mathrm{~g}$ more on $\mathrm{d} 7 \mathrm{~g}$ life at L2 compared to L1, they gained about 350 to 400 g less by d 36 at L2 compared to L1 $(P<0.001)$. In contrast, 
TFI between $\mathrm{d} 7$ and 36 of life was not influenced by location. Likewise, location did not affect the FE metrics RFI, RBG and RIG; providing similar values for female and male chickens of the same RFI group, whereas FCR was about $12 \%$ lower $(\mathrm{P}<0.001)$ in chickens of L1 compared to chickens of L2.

The RFI ranged on average from -231 to $215 \mathrm{~g}$ in females and from -197 to $267 \mathrm{~g}$ in males representing a difference of 330 and $500 \mathrm{~g}$ TFI between most and least efficient female and male chickens $(P<0.001$; Table 1 and 2$)$. Body weight at d 36 and TBWG were similar among chickens of diverging RFI. Likewise, the RBG of the selected chickens was similar among the three RFI groups, whereas the RIG linearly decreased in the same range observed for the increase in RFI from low to high RFI chickens, irrespective of sex. The FCR linearly increased from low to high RFI by on average $13 \%(P<0.001)$. There was a sex effect and location effect for FCR showing a $0.06 \mathrm{~g} / \mathrm{g}$-lower FCR in males compared to females as well as a $0.19 \mathrm{~g} / \mathrm{g}$ lower FCR in chickens at L1 compared to chickens at L2 $(P<0.001)$.

At sacrifice, male chickens at both locations had similar BW across locations (3.03 and $3.02 \pm 0.062 \mathrm{~kg}$ at L1 and L2, respectively; $P=0.859)$ and RFI groups $(3.04,2.96$ and $3.08 \pm$ $0.076 \mathrm{~kg}$ for low, medium and high RFI, respectively; $P=0.535)$. By contrast, $\mathrm{BW}$ in female chickens at sacrifice differed across locations with females at L1 weighing about 270 g more than females at L2 (2.85 versus $2.58 \pm 0.063 \mathrm{~kg}$ at L1 versus L2, respectively; $P=0.001)$, but their BW was not different among RFI groups $(2.72,2.71$ and $2.73 \pm 0.065$ for low, medium and high RFI, respectively; $P=0.974)$.

\section{Serum metabolite profiles and acute phase proteins}

Results for serum metabolite profiles and acute-phase-proteins examined for female and male chickens are presented in Table 3 and 4, respectively. There was a location effect for serum OVT in females showing that chickens at L1 had a 2-fold higher serum OVT concentration than that of chickens at L2 $(P<0.05)$. Moreover, we observed a linear increase $(P<0.05)$ in 
serum AGP from low to high RFI in male chickens at L1 but not at L2. Sex affected $(P<$ 0.05) serum NEFA concentrations which were higher in males. Female chickens at L1 had a lower serum glucose and NEFA and higher serum urea and cholesterol than females at L2 ( $P$ $<0.05)$. In males, serum glucose and triglycerides were lower at L1 compared to L2 $(P<$ 0.01). Despite differences in actual serum concentrations, FE-effects for glucose, uric acid and cholesterol among RFI groups were similar at both locations in females. There was a linear increase in serum uric acid $(P<0.05)$, and a tendency for a linear increase in serum cholesterol and triglycerides $(P<0.1)$ from low to high RFI in female chickens. Serum NEFA showed a FE $\times$ location effect $(\mathrm{P}<0.01)$ by increasing by $57 \%$ from low to high RFI at L2 but not in females at L1. Similar to the females, serum cholesterol linearly increased $(\mathrm{P}<$ $0.05)$ and triglycerides tended $(P<0.1)$ to increase by about 17 and $31 \%$ from low to high RFI in male chickens, respectively.

\section{White blood cell counts}

White blood cell counts were only determined at L1 (Table 5). Females and males differed in their white blood cell counts with females having more lymphocytes but less monocytes and heterophils than males $(P<0.05)$. In females, FE tended to affect only monocyte counts with chickens of low RFI having less monocytes than chickens of medium and high RFI. In males, lymphocyte counts linearly decreased $(P=0.012)$ from low to high RFI, whereas heterophils linearly increased from low to high RFI $(P=0.031)$. Because of this, there was a linear $(P=$ 0.027 ) increase in the H-to-L ratio of $68 \%$ from low to high RFI in males.

\section{Multivariate and regression analysis}

The LDA plot of RFI groups and serum metabolites showed separate clustering for serum metabolites for low and high RFI, whereas the $95 \%$ confidence intervals of medium RFI overlapped with those of low and high RFI (Figure 1A). Serum glucose discriminated best for 
low RFI, whereas serum triglycerides, uric acid and cholesterol correlated with high RFI.

When comparing locations (Figure 1B), the LDA showed clear clustering of serum metabolites between L1 and L2, whereby serum NEFA correlated to L2 and urea to L1. Due to the separate clustering in the LDA together with trends for linear relationships between some serum metabolites and RFI groups, relationships between serum parameters and the individual RFI values of chickens from both sexes and locations were regressed. Regression analysis showed positive relationships between serum cholesterol and RFI $\left(R^{2}=0.13 ; P<\right.$ 0.001; Figure 2A) and serum uric acid and RFI $\left(R^{2}=0.49 ; P<0.001\right.$; Figure $\left.2 \mathrm{~B}\right)$. There was also a weak positive relationship between the H-to-L ratio and RFI values for chickens at L1 $\left(R^{2}=0.15 ; P=0.003 ;\right.$ Figure $\left.2 \mathrm{C}\right)$.

\section{Discussion}

Our understanding of the physiological mechanisms underlying the FE of chicken's is steadily advancing (e.g., Aggrey et al., 2014; Lee et al., 2015; Zhou et al., 2015). However, the contribution of the rearing environment has not yet been sufficiently elucidated. In the current study, chickens from one hybrid line were raised using similar management protocols at two distinct geographic locations to investigate if RFI-related performance traits and serum profiles are affected by the rearing environment. Similar to Stanley et al. (2016), the present chicken populations met or exceeded the expected average growth rate, and the range in TFI, growth, and FE data recorded was consistent with previous studies in chickens selected for RFI (e.g., Zhuo et al., 2015). Although the TFI from d 7 to 36 of life was similar across locations, results indicated a marked location effect on TBWG of chickens between locations which was apparent throughout all replicate batches and for both sexes. Furthermore, we could distinguish RFI-related profiles for certain serum intermediary metabolites, but not acute-phase-proteins, in the current chicken populations, whereby RFI-effects were different in males and females. The regression models implemented established linear relationships 
between RFI and serum uric acid and cholesterol, suggesting them as predictors for RFI in the current chicken populations irrespective of sex and location. Despite these relationships and clear clustering between low and high RFI in the LDA plots, the actual concentrations of serum metabolites were location-specific which may render it difficult to predict universal serum threshold values for low, medium and high RFI chickens. Moreover, as present relationships between RFI and serum cholesterol and uric acid were weak to moderate, it may be advisable to use serum metabolite patterns rather than individual metabolites to predict the RFI in chickens.

Chicken RFI values were similar across locations, but it should be considered that chicken's RFI values were determined two-days apart. The RFI is phenotypically independent of BW and level of production (e.g., ADG; Bottje and Carstens, 2009), and may have therefore remained similar across locations in the current study despite differences in TBWG and ADG. Similar observations were made for RBG and the combined metric RIG of the selected chickens. Inconsistent findings exist in the literature for RFI-related differences in BW and BW gain in low and high RFI chickens (van Eerden et al., 2004; Zhuo et al., 2015). Irrespective of location, chickens of diverging RFI could not be distinguished based on their BW or TBWG. In contrast to some studies with short measurement periods of only one week (e.g., Zhuo et al., 2015), we determined the FE over a period of 29 and 31 days at L1 and L2, respectively. It is highly likely that this improved the accuracy of RFI prediction in the present study as we observed slight differences in the FE and grouping of chickens according to their RFI when assessed only on a weekly basis. Differences in TFI between low and high RFI chickens were considerable and were already present at 21 days of life (Supplemental Table 1). Notably, irrespective of the two-day difference in selection for RFI, location effects were distinguishable when using the ratio metric FCR. This leads to the assumption that the FCR may more accurately predict FE-related differences in growth performance among 
chicken flocks, whereas the RFI may be the FE metric of choice to equally rank chickens independent from the environment.

The present environmental effects clearly suggest that physiological differences between low and high RFI chickens may largely vary between farms due to environment-specific factors. Parents' own FE essentially determines development and FE of the chicks post-hatch (Bottje and Carstens, 2009; Romero et al., 2011). This may have been of less relevance in the present study as chickens used in the present trials were not related within or between locations (see Relationship analysis in Supplemental Material). The main environmentspecific factors were likely the diet, even though it was of the same formulation, the housing environment including environmental microbes at the hatcheries and rearing location as well as the personnel handling the chickens. The immediate colonization of chicken's intestine post-hatch with microbes from the egg shell and environment is critical because it has a long lasting effect on chicken's performance by influencing the further microbial colonization, intestinal development and priming of the immune system (Brisbin et al., 2008; Schokker et al., 2015). The intestinal microbiota interacts with the host via several routes including microbial metabolites and receptor-recognition pathways (Blaut, 2015). As a result, different bacterial colonization patterns may have caused a more pronounced stimulation of the immune system throughout the growing phase at one location which may have decreased the energy available for growth. Also, different bacterial colonization across locations may have led to diverging profiles of intestinally produced short-chain fatty acids which, after being absorbed, may have affected lipogenesis of the host and present serum profiles. Especially acetate serves as substrate for de novo lipogenesis in the liver, whereas propionate is used for hepatic gluconeogenesis (Blaut, 2015). In general, due to the hygienic standards in modern hatcheries, microbial colonization of the gastrointestinal tract of newly hatched chicks is more influenced by microbes encountered in their wider environment (e.g., personnel, housing, water and diet) than by the normal chicken gut microbiota (Stanley et al., 2013; Ludvigsen et 
al., 2016). Because current chickens came from different hatcheries, the early microbial colonization may have been one of the most influential factors for the variation between both locations. This would be supported by different RFI-associated bacterial microbiome profiles in chickens between the two locations at 6 weeks of life (Siegerstetter et al., 2016). Moreover, although the dietary formulations were the same and concentrations of most nutrients were equal, natural differences in the raw materials, i.e. corn and soybean meal, between locations (e.g. dietary fiber composition; Rodehutscord et al., 2016) may have altered digestive, absorptive and fermentative processes. This probably affected the present results for growth performance and serum metabolite profiles across locations.

The BW at sacrifice and thus body composition may have also contributed to the variation in serum parameters in female chickens across locations and were likely depicted in chickens' serum metabolite and APP concentrations. Accordingly, serum profiles suggested that chickens at L2 had either an increased intestinal glucose release or altered systemic glucose metabolism than those at L1, irrespective of sex. Moreover, differences in BW and thus adipose tissue accretion likely led to the variation in serum lipids across locations. Moreover, the increased OVT response in females at L1 compared to L2 may indicate an increased abundance of microbial stressors at L1. As an iron binding protein OVT provides antimicrobial properties by sequestering iron and modulates heterophil and macrophage function in chickens (Murata et al., 2004). In spite of the observed location effects, the fact that location $\times \mathrm{FE}$ interactions were almost absent in our study allows assuming that RFIrelated differences in performance traits and serum profiles were similar across locations.

Although influenced by prandial activity, blood metabolites and hormones associated with feed intake, growth, nutrient repartitioning and utilization may serve as potential physiological markers for FE in various livestock species (Richardson et al., 2004; Kelly et al., 2010; Montagne et al., 2014; Jegou et al., 2016). Likewise, serum intermediary metabolites suggest RFI-related differences in systemic lipid and protein metabolism in the 
chicken populations of the present study. Controversial results were previously reported for serum triglycerides, NEFA and uric acid in cockerel lines selected for low and high RFI (Gabbarou et al., 1997; Swennen et al., 2007), whereas, to our awareness, little information exists for broiler chickens of diverging RFI. Although the selection strategy and age of the chickens differed, Gabbarou et al. (1997) found a comparable increase in plasma triglycerides and plasma glucose and uric acid concentrations in cockerels which corresponded to our results in male chickens. According to the present linear FE-effects and regression analysis, serum concentrations of uric acid and serum cholesterol might be considered as predictors for RFI in chickens. The higher FI in high RFI chickens should have increased the intestinal glucose uptake and postprandial insulin level as well as peak duration. Accordingly, equal serum glucose concentrations may indicate improved energy saving capacity or lower glucose uptake and metabolism of peripheral organs in low versus high RFI chickens (Bottje and Carstens, 2009). Some authors (Richardson et al., 2004; Kelly et al., 2010) have proposed a decrease in insulin sensitivity in muscle tissue in energetically inefficient animals.

Concurrently, higher basal insulin concentrations in high-RFI animals may be linked to greater fat deposition because insulin reduces lipolysis and stimulates lipogenesis in adipose tissue (Kelly et al., 2010; Le Naou et al., 2012; Montagne et al., 2014; Zhuo et al., 2015). Accordingly, Zhuo et al. (2015) showed that abdominal adipose tissue of high RFI chickens had a greater expression of lipid synthesis genes and decreased expression of triglyceride hydrolysis and cholesterol transport genes. Moreover, in their study, low RFI chickens had a potentially more active glucose-to-lipid conversion and different insulin signaling in adipose tissue at transcriptome level compared to high RFI chickens (Zhuo et al., 2015). The latter may explain the elevated postprandial serum triglycerides and cholesterol observed for high RFI males and females compared to their low RFI counterparts in the present study. Varying RFI-related serum profiles in males and females indicated that differences were more pronounced in females than males. Despite not having measured serum insulin levels, 
elevated serum uric acid and NEFA in high RFI females may confirm our assumption of reduced insulin sensitivity since both metabolites are typically raised during insulin resistance due to increased lipolysis and deamination of amino acids for energy provision (e.g., Yuan et al., 2008; Ji et al., 2012). In addition, raised serum uric acid in high RFI animals may also suggest less efficient nitrogen recycling as recently shown for a different chicken line (Aggrey et al., 2014).

Inconclusive results exist on whether diverging RFI is accompanied by a change in the stress response of meat-type chickens. As part of the physiological stress response via the hypothalamic-pituitary-adrenal axis and sympathetic system, increased systemic levels of corticosterone induces a general acute-phase response including OVT and AGP in chickens (O’Reilly and Eckersall, 2014; Zulkifli et al., 2014). Moreover, increased corticosterone levels were associated with modified insulin sensitivity, reduced muscle protein accretion and raised plasma lipids and uric acid in chickens (Dong et al., 2007; Yuan et al., 2008) which may have contributed to RFI-related metabolic alterations and serum metabolite profiles. Present results for RFI-related differences in serum APPs were not, however, conclusive and only indicated a linear relationship between AGP and RFI in males at L1. Similar to AGP, the H-to-L ratio showed the same RFI-related pattern in males at L1 only. AGP has an immunoregulatory function by influencing T-cell function and thus white blood cell production (Murata et al., 2004). Since males and females were evenly distributed across the experimental room for all three batches at L1, a greater immune response due to infectious disease agents may be excluded as an explanation for the gender difference seen here. The question then arises as to whether the high RFI males at L1 showed a greater excitability or aggressiveness compared to the female chickens. Despite the weak linear relationship between RFI and serum H-to-L, its reliability to predict chicken's RFI should be evaluated in further experiments since only data from L1 were available for regression analysis in the present study. 
In conclusion, the results of the present study demonstrate that chickens reared at two geographically distinct locations showed similar RFI-related variation in serum intermediary metabolites. Regression analysis confirmed the usefulness of serum metabolite patterns as RFI predictors for the current chicken populations. Due to the environment-specific differences observed here, further research is warranted to validate the reliability of serum metabolites, such as uric acid and cholesterol, as RFI predictors in chickens.

\section{Acknowledgements}

This project (ECO-FCE) has received funding from the European Union's Seventh Framework Programme for research, technological development and demonstration (grant no. 311794). The technical staff at the Institute of Animal Nutrition and Functional Plant Compounds (University of Veterinary Medicine Vienna) and at the Agri-Food and Biosciences Institute are gratefully thanked for their care of the animals and expertise when conducting the experiment and for laboratory assistance.

\section{Disclosure statement}

The authors state no conflict of interest.

\section{References}

AGGREY, S.E., LEE, J., KARNUAH, A.B. \& REKAYA, R. (2014) Transcriptomic analysis of genes in the nitrogen recycling pathway of meat-type chickens divergently selected for feed efficiency. Animal Genetics 45: 215-222. doi:10.1111/age.12098

BERRY, D.P. \& CROWLEY, J.J. (2012) Residual intake and body weight gain: A new measure of efficiency in growing cattle. Journal of Animal Science 90:109-115. doi:10.2527/jas.2011-4245 
BLAUT, M. (2015) Gut microbiota and energy balance: role in obesity. The Proceedings of the Nutrition Society 74:227-234. doi: 10.1017/S0029665114001700.

BOTTJE, W.G. \& CARSTENS, G.E. (2009) Association of mitochondrial function and feed efficiency in poultry and livestock species. Journal of Animal Science 87:E48-E63. doi:10.2527/jas.2008-1379

BRISBIN, J.T., GONG, J., and SHARIF, S. (2008) Interactions between commensal bacteria and the gut-associated immune system of the chicken. Animal Health Research Reviews 9:101-110. doi: 10.1017/S146625230800145X.

DONG, H., LIN, H., JIAO, H.C., SONG, Z.G., ZHAO, J.P. \& JIANG, K.J. (2007) Altered development and protein metabolism in skeletal muscles of broiler chickens (Gallus gallus domesticus) by corticosterone. Comparative Biochemistry and Physiology Part A: Molecular \& Integrative Physiology 147:189-195.

GABARROU, J. F., GÉRAERT, P.A., PICARD, M. \& BORDAS, A. (1997) Diet-induced thermogenesis in cockerels is modulated by genetic selection for high or low residual feed intake. Journal of Nutrition 127:2371-2376.

GROSS, W.B. \& SIEGEL, H.S. (1983) Evaluation of the heterophil/lymphocyte ratio as a measure of stress in chickens. Avian Disease 27:972-979.

HERD, R.M. \& ARTHUR, P.F (2009) Physiological basis for residual feed intake. Journal of Animal Science 87:E64-E71.

JÉGOU, M., GONDRET, F., VINCENT, A., TRÉFEU, C., GILBERT, H. \& LOUVEAU, I. (2016) Whole blood transcriptomics is relevant to identify molecular changes in response to genetic selection for feed efficiency and nutritional status in the pig. PLoS One 11:e0146550. doi: 10.1371/journal.pone.0146550.

JI, B., ERNEST, B., GOODING, J.R., DAS, S., SAXTON, A.M., SIMON, J., DUPONT, J., MÉTAYER-COUSTARD, S., CAMPAGNA, S. R., \& VOY, B.H. (2012) Transcriptomic and metabolomic profiling of chicken adipose tissue in response to 
insulin neutralization and fasting. BMC Genomics 13:441. doi: 10.1186/1471-2164-13441

KELLY, A.K., MCGEE, M., CREWS JR., D.H.,SWEENEY, T., BOLAND, T.M., \& KENNY, D.A. (2010) Repeatability of feed efficiency, carcass ultrasound, feeding behavior, and blood metabolic variables in finishing heifers divergently selected for residual feed intake. Journal of Animal Science 88:3214-3225. doi:10.2527/jas.20092700

LE NAOU, T., LE FLOC'H, N., LOUVEAU, I., GILBERT, H., \& GONDRET, F. 2012. Metabolic changes and tissue responses to selection on residual feed intake in growing pigs. Journal of Animal Science 90:4771-4780. doi: 10.2527/jas.2012-5226.

LEE, J., KARNUAH, A.B., REKAYA, R., ANTHONY, N.B. \& AGGREY, S.E. (2015) Transcriptomic analysis to elucidate the molecular mechanisms that underlie feed efficiency in meat-type chickens. Molecular Genetics and Genomics 290:1673-82. doi: $10.1007 / \mathrm{s} 00438-015-1025-7$

LUDVIGSEN, J., SVIHUS, B., RUDI, K. (2016) Rearing room affects the non-dominant chicken cecum microbiota, while diet affects the dominant microbiota. Frontiers in Veterinary Science 5(3):16. doi: 10.3389/fvets.2016.00016.

METZLER-ZEBELI, B.U., MOLNÁR, A., HOLLMANN, M., MAGOWAN, E., HAWKEN, R., LAWLOR, P.G. \& ZEBELI, Q. (2016) Comparison of growth performance and excreta composition in broiler chickens when ranked according to various feed efficiency metrics. Journal of Animal Science 94:2890-2899. doi: 10.2527/jas.20160375.

MIGNON-GRASTEAU, S., NARCY, A., RIDEAU, N., CHANTRY-DARMON, C., BOSCHER, M.Y., SELLIER, N., CHABAULT, M., KONSAK-ILIEVSKI, B., LE BIHAN-DUVAL, E. \& GABRIEL, I. (2015) Impact of selection for digestive efficiency 
on microbiota composition in the chicken. PLoS One 10(8):e0135488. doi:10.1371/journal.pone.0135488

MONTAGNE, L., LOISEL, F., LE NAOU, T., GONDRET, F., GILBERT, H. \& LE GALL, M. (2014) Difference in short-term responses to a high-fiber diet in pigs divergently selected for residual feed intake. Journal of Animal Science 92:1512-1523.

MURATA, H., SHIMADA, N. \& YOSHIOKA, M. (2004) Current research on acute phase proteins in veterinary diagnosis: An overview. Veterinary Journal 168:28-40.

NAUMANN, C. \& BASLER, R. (2012) Die chemische Untersuchung von Futtermitteln (Darmstadt, Germany, VDLUFA Verlag).

O’REILLY, E.L. \& ECKERSALL, P.D. (2014) Acute phase proteins: A review of their function, behaviour and measurement in chickens. World's Poultry Science Journal 70:27-44.

Richardson, E.C., Herd, R.M., Archer, J.A. \& Arthur, P.F. (2004) Metabolic differences in Angus steers divergently selected for residual feed intake. Australian Journal of Experimental Agriculture 44:441-452.

RODEHUTSCORD, M., RÜCKERT, C., MAURER, H.P., SCHENKEL, H., SCHIPPRACK, W., BACH KNUDSEN, K.E., SCHOLLENBERGER, M., LAUX, M., EKLUND, M., SIEGERT, W. \& MOSENTHIN, R. (2016) Variation in chemical composition and physical characteristics of cereal grains from different genotypes. Archives in Animal Nutrition 70:87-107. doi: 10.1080/1745039X.2015.1133111.

ROMERO, L.F., ZUIDHOF, M.J., RENEMA, R.A., NAEIMA, A. \& ROBINSON, F.E. (2011) Effects of maternal energy efficiency on broiler chicken growth, feed conversion, residual feed intake, and residual maintenance metabolizable energy requirements. Poultry Science 90:2904-2912. doi: 10.3382/ps.2011-01665

SCHOKKER, D., VENINGA, G., VASTENHOUW, S.A., BOSSERS, A., DE BREE, F.M., KAAL-LANSBERGEN, L.M., REBEL, J.M. \& SMITS, M.A. (2015) Early life 
microbial colonization of the gut and intestinal development differ between genetically divergent broiler lines. BMC Genomics 16:418. doi: 10.1186/s12864-015-1646-6.

SIEGERSTETTER, S.-C., PETRI, R.M., MAGOWAN, E., ZEBELI, Q., LAWLOR, P.G. \& METZLER-ZEBELI, B.U. (2016) ECO-FCE: Feed efficiency related gut microbiota profiles vary in chickens raised at two locations. 67th Annual Meeting of the European Federation of Animal Science, p. 200, August 29-September 2, Belfast.

STANLEY, D., GEIER, M.S., HUGHES, R.J., DENMAN, S.E. \& MOORE, R.J. (2013) Highly variable microbiota development in the chicken gastrointestinal tract. PLOS ONE 8(12): e84290. doi:10.1371/journal.pone.0084290

STANLEY D., HUGHES, R.J., GEIER, M.S. \& MOORE, R.J. (2016) Bacteria within the gastrointestinal tract microbiota correlated with improved growth and feed conversion: challenges presented for the identification of performance enhancing probiotic bacteria. Frontiers in Microbiology 7:187. doi: 10.3389/fmicb.2016.00187.

SWENNEN, Q., VERHULST, P.-J., COLLIN, A., BORDAS, A., VERBEKE, K., VANSANT, G., DECUYPÈRE, E. \& BUYSE, J. (2007) Further investigations on the role of diet-induced thermogenesis in the regulation of feed intake in chickens: comparison of adult cockerels of lines selected for high or low residual feed intake. Poultry Science 86:1960-1971.

VAN ERDEN , E., VAN DEN BRAND, H., PARMENTIER, H.K., DE JONG, M.C.M. \& KEMP, B. (2004) Phenotypic selection for residual feed intake and its effect on humoral immune responses in growing layer hens. Poultry Science 83:1602-1609.

YUAN, L., LIN, H., JIANG, K.J., JIAO, H.C. \& SONG, Z.G. (2008) Corticosterone administration and high-energy feed results in enhanced fat accumulation and insulin resistance in broiler chickens. British Poultry Science 49:487-495. doi: $10.1080 / 00071660802251731$. 
ZHUO, Z., LAMONT, S.J., LEE, W.R. \& ABASHT, B. (2015) RNA-Seq Analysis of Abdominal Fat Reveals Differences between Modern Commercial Broiler Chickens with High and Low Feed Efficiencies. PLoS One 10(8):e0135810. doi: 10.1371/journal.pone.0135810.

ZULKIFLI, I., CHE NORMA, M.T., CHONG, C.H. \& LOH, T.C. (2000) Heterophil to lymphocyte ratio and tonic immobility reactions to preslaughter handling in broiler chickens treated with ascorbic acid. Poultry Science 79:402-406.

ZULKIFLI, I., NAJAFI, P., NURFARAHIN, A.J., SOLEIMANI, A.F., KUMARI, S., ARYANI, A.A., O'REILLY, E.L. \& ECKERSALL, P.D. (2014) Acute-phase proteins, interleukin 6, and heat shock protein 70 in broiler chickens administered with corticosterone. Poultry Science 93:3112-3118. doi: 10.3382/ps.2014-04099. 
Table 1. Feed intake, growth performance and feed efficiency metrics in female broiler chickens raised at two different locations.

\begin{tabular}{|c|c|c|c|c|c|c|c|c|}
\hline \multirow[b]{2}{*}{ Item } & \multirow[b]{2}{*}{ Location } & \multicolumn{3}{|c|}{ Residual feed intake (RFI) $)^{1,2}$} & \multirow[b]{2}{*}{ SEM } & \multicolumn{3}{|c|}{$P$-value ${ }^{3,4}$} \\
\hline & & Low & Medium & High & & $\mathrm{FE}$ & location & $\mathrm{FE} \times$ location \\
\hline \multirow[t]{3}{*}{ BW, d 7 of life (g) } & $\mathrm{L} 1+2$ & 145 & 145 & 147 & 2.6 & 0.805 & 0.001 & 0.802 \\
\hline & L1 & 141 & $138^{y}$ & $141^{\mathrm{y}}$ & 3.6 & & & \\
\hline & $\mathrm{L} 2$ & 149 & $151^{\mathrm{x}}$ & $153^{\mathrm{x}}$ & 2.6 & & & \\
\hline \multirow[t]{3}{*}{ BW, d 36 of life (g) } & $\mathrm{L} 1+2$ & 2253 & 2187 & 2215 & 50.4 & 0.654 & $<0.001$ & 0.670 \\
\hline & L1 & $2392^{x}$ & $2359^{x}$ & $2420^{x}$ & 68.9 & & & \\
\hline & $\mathrm{L} 2$ & $2115^{y}$ & $2015^{y}$ & $2009^{y}$ & 73.2 & & & \\
\hline \multirow[t]{3}{*}{ Total feed intake, d 7-36 of life (g) } & $\mathrm{L} 1+2$ & $3447^{b}$ & $3485^{\mathrm{ab}}$ & $3774^{\mathrm{a}}$ & 91.1 & $0.027^{*}$ & 0.479 & 0.566 \\
\hline & L1 & $3334^{\mathrm{b}}$ & $3510^{\mathrm{ab}}$ & $3751^{a}$ & 123.2 & & & \\
\hline & $\mathrm{L} 2$ & 3559 & $3461^{\mathrm{B}}$ & $3797^{\mathrm{A}}$ & 131.0 & & & \\
\hline \multirow[t]{3}{*}{ Total body weight gain, d 7-36 of life (g) } & $\mathrm{L} 1+2$ & 2108 & 2042 & 2068 & 49.5 & 0.647 & $<0.001$ & 0.643 \\
\hline & L1 & $2251^{x}$ & $2220^{x}$ & $2279^{x}$ & 67.7 & & & \\
\hline & $\mathrm{L} 2$ & $1966^{y}$ & $1865^{y}$ & $1856^{\mathrm{y}}$ & 72.0 & & & \\
\hline \multirow[t]{3}{*}{ RFI (g) } & $\mathrm{L} 1+2$ & -231 & 8 & 215 & 20.1 & $<0.001 * * *$ & 0.412 & 0.201 \\
\hline & L1 & -195 & 18 & 197 & 27.5 & & & \\
\hline & $\mathrm{L} 2$ & -267 & -3 & 232 & 29.2 & & & \\
\hline \multirow[t]{3}{*}{ RBG (g) } & $\mathrm{L} 1+2$ & -0.9 & 1.0 & 1.7 & 4.13 & 0.901 & 0.775 & 0.993 \\
\hline & L1 & -2.1 & 0.5 & 1.3 & 5.65 & & & \\
\hline & $\mathrm{L} 2$ & 0.2 & 1.5 & 2.1 & 6.01 & & & \\
\hline \multirow[t]{3}{*}{ RIG (g) } & $\mathrm{L} 1+2$ & 230 & -7 & -213 & 20.2 & $<0.001 * * *$ & 0.380 & 0.195 \\
\hline & L1 & 193 & -18 & -196 & 27.6 & & & \\
\hline & $\mathrm{L} 2$ & 267 & 4 & -231 & 29.3 & & & \\
\hline
\end{tabular}


FCR $(g / g)$

$\begin{array}{lll}\mathrm{L} 1+2 & 1.55 & 1.63\end{array}$

1.63

1.76

0.019

$<0.001 * * *$

$<0.001$

0.108

L2 $1.65^{\mathrm{x}} \quad 1.71^{\mathrm{x}} \quad 1.89^{\mathrm{x}} \quad 0.028$

$1.65^{\mathrm{x}}$ 0.028

607 Agri-Food and Biosciences Institute (Hillsborough, Northern Ireland, UK)

${ }^{1}$ Values are least squares means \pm standard error of the mean (SEM).

${ }^{2}$ Each RFI group represents $n=9$ female chickens at location $1 ; n=6$ low RFI, $n=11$ medium RFI and $n=8$ high RFI females at location 2 .

$610{ }^{3} P$ : probability level.

$611{ }^{4}$ Linear polynominal contrast: $* P \leq 0.05$, and $* * * P \leq 0.001$.

${ }^{\text {a-c }}$ Least squares means within a row without a common lowercase superscript differ among RFI groups $(P<0.05)$.

613 A,B Least squares means within a row without a common uppercase superscript tend to differ among RFI groups $(P<0.1)$.

$614{ }^{\mathrm{x}, \mathrm{y}}$ Least squares means within a column without a common lowercase superscript differ between locations $(P<0.05)$. 
616 Table 2. Feed intake, growth performance and feed efficiency metrics in male broiler chickens raised at two different locations.

\begin{tabular}{|c|c|c|c|c|c|c|c|c|}
\hline \multirow[b]{2}{*}{ Item } & \multirow[b]{2}{*}{ Location } & \multicolumn{3}{|c|}{ Residual feed intake (RFI) $)^{1,2}$} & \multirow[b]{2}{*}{ SEM } & \multicolumn{3}{|c|}{$P$-value ${ }^{3,4}$} \\
\hline & & Low & Medium & High & & $\mathrm{FE}$ & location & $\mathrm{FE} \times$ location \\
\hline \multirow[t]{3}{*}{ BW, d 7 of life (g) } & $\mathrm{L} 1+2$ & 145 & 145 & 148 & 2.2 & 0.704 & $<0.001$ & 0.919 \\
\hline & L1 & $139^{x}$ & $140^{\mathrm{x}}$ & $141^{\mathrm{x}}$ & 3.0 & & & \\
\hline & $\mathrm{L} 2$ & $152^{y}$ & $150^{\mathrm{y}}$ & $154^{y}$ & 3.0 & & & \\
\hline \multirow[t]{3}{*}{ BW, d 36 of life (g) } & $\mathrm{L} 1+2$ & 2562 & 2483 & 2546 & 55.4 & 0.577 & $<0.001$ & 0.560 \\
\hline & L1 & $2712^{x}$ & $2733^{x}$ & $2756^{\mathrm{x}}$ & 79.0 & & & \\
\hline & $\mathrm{L} 2$ & $2380^{y}$ & $2233^{y}$ & $2367^{y}$ & 79.4 & & & \\
\hline \multirow[t]{3}{*}{ Total feed intake, d 7-36 of life (g) } & $\mathrm{L} 1+2$ & $3753^{b}$ & $3879^{b}$ & $4253^{a}$ & 70.1 & $<0.001 * * *$ & 0.340 & 0.573 \\
\hline & L1 & $3682^{b}$ & $3901^{b}$ & $4185^{\mathrm{a}}$ & 99.9 & & & \\
\hline & $\mathrm{L} 2$ & $3823^{\mathrm{b}}$ & $3857^{\mathrm{b}}$ & $4321^{a}$ & 98.2 & & & \\
\hline \multirow[t]{3}{*}{ Total body weight gain, d 7-36 of life (g) } & $\mathrm{L} 1+2$ & 2401 & 2338 & 2414 & 54.5 & 0.582 & $<0.001$ & 0.560 \\
\hline & L1 & 2573 & $2593^{x}$ & $2615^{x}$ & 77.7 & & & \\
\hline & $\mathrm{L} 2$ & 2228 & $2083^{y}$ & $2214^{y}$ & 76.4 & & & \\
\hline \multirow[t]{3}{*}{ RFI } & $\mathrm{L} 1+2$ & -197 & 0 & 267 & 21.8 & $<0.001 * * *$ & 0.149 & 0.610 \\
\hline & L1 & -183 & 6 & 303 & 31.1 & & & \\
\hline & $\mathrm{L} 2$ & -211 & -6 & 231 & 30.6 & & & \\
\hline \multirow[t]{3}{*}{ RBG } & $\mathrm{L} 1+2$ & 5.5 & -1.1 & 3.8 & 4.40 & 0.550 & 0.166 & 0.687 \\
\hline & L1 & 6.8 & 1.8 & 10.4 & 6.27 & & & \\
\hline & L2 & 4.2 & -3.9 & -2.7 & 6.16 & & & \\
\hline \multirow[t]{3}{*}{ RIG } & $\mathrm{L} 1+2$ & 202 & -1 & -263 & 22.0 & $<0.001 * * *$ & 0.247 & 0.699 \\
\hline & L1 & 190 & -4 & -292 & 31.3 & & & \\
\hline & $\mathrm{L} 2$ & 215 & 2 & -234 & 30.8 & & & \\
\hline
\end{tabular}


FCR

$\begin{array}{lll}\mathrm{L} 1+2 & 1.50 \quad 1.58\end{array}$

1.58

1.70

0.019

$<0.001 * * *$

$<0.001$

0.774

L2

$1.58^{\mathrm{x}}$

$1.69^{\mathrm{x}}$

$1.79^{\mathrm{x}}$

0.027

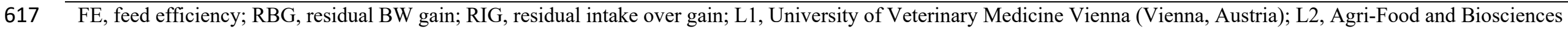

618 Institute (Hillsborough, Northern Ireland, UK).

$619{ }^{1}$ Values are least squares means \pm standard error of the mean (SEM)

62

$621{ }^{3}$ P: probability level.

$622{ }^{4}$ Linear polynominal contrast: $* * * P \leq 0.001$.

$623{ }^{\mathrm{a}-\mathrm{c}}$ Least squares means within a row without a common lowercase superscript differ among RFI groups $(P<0.05)$.

$624{ }^{\mathrm{x}, \mathrm{y}}$ Least squares means within a column without a common lowercase superscript differ between locations $(P<0.05)$ 
626 Table 3. Serum metabolites and acute-phase-proteins in female broiler chickens raised at two different locations.

\begin{tabular}{|c|c|c|c|c|c|c|c|c|}
\hline \multirow[b]{2}{*}{ Parameter } & \multirow[b]{2}{*}{ Location } & \multicolumn{3}{|c|}{ Residual feed intake ${ }^{1,2}$} & \multirow[b]{2}{*}{ SEM } & \multicolumn{3}{|c|}{$P$-value ${ }^{3,4}$} \\
\hline & & Low & Medium & High & & FE & location & $\mathrm{FE} \times$ location \\
\hline \multirow[t]{3}{*}{ Glucose $(\mathrm{mg} / \mathrm{dl})$} & $\mathrm{L} 1+2$ & 304 & 283 & 310 & 16.8 & 0.450 & 0.002 & 0.920 \\
\hline & L1 & $268^{\mathrm{X}}$ & $256^{\mathrm{X}}$ & $276^{\mathrm{x}}$ & 23.0 & & & \\
\hline & $\mathrm{L} 2$ & $340^{\mathrm{Y}}$ & $310^{\mathrm{Y}}$ & $344^{y}$ & 24.4 & & & \\
\hline \multirow[t]{3}{*}{ Urea (mg/dl) } & $\mathrm{L} 1+2$ & $2.27^{\mathrm{b}}$ & $2.42^{\mathrm{ab}}$ & $2.83^{\mathrm{a}}$ & 0.182 & $0.101 *$ & 0.005 & 0.701 \\
\hline & L1 & $2.46^{\mathrm{b}}$ & $2.76^{\mathrm{abx}}$ & $3.25^{\mathrm{ax}}$ & 0.248 & & & \\
\hline & $\mathrm{L} 2$ & 2.08 & $2.08^{\mathrm{y}}$ & $2.41^{\mathrm{y}}$ & 0.264 & & & \\
\hline \multirow[t]{3}{*}{ Cholesterol (mg/dl) } & $\mathrm{L} 1+2$ & 132 & 138 & 145 & 5.1 & $0.244 \dagger$ & 0.002 & 0.628 \\
\hline & L1 & 139 & $152^{\mathrm{X}}$ & 154 & 7.0 & & & \\
\hline & $\mathrm{L} 2$ & 125 & $125^{\mathrm{Y}}$ & 135 & 7.4 & & & \\
\hline \multirow[t]{3}{*}{ Triglycerides (mg/dl) } & $\mathrm{L} 1+2$ & $93^{\mathrm{B}}$ & 101 & $126^{\mathrm{A}}$ & 11.8 & $0.135 \dagger$ & 0.802 & 0.882 \\
\hline & L1 & $86^{\mathrm{B}}$ & 103 & $126^{\mathrm{A}}$ & 16.2 & & & \\
\hline & $\mathrm{L} 2$ & 99 & 99 & 127 & 17.2 & & & \\
\hline \multirow[t]{3}{*}{ NEFA $(\mu \mathrm{mol} / 1)$} & $\mathrm{L} 1+2$ & 204 & 241 & 269 & 11.6 & $0.002 * * *$ & $<0.001$ & 0.008 \\
\hline & L1 & 199 & $214^{y}$ & $208^{y}$ & 15.8 & & & \\
\hline & $\mathrm{L} 2$ & $210^{\mathrm{c}}$ & $269^{\mathrm{bx}}$ & $330^{\mathrm{ax}}$ & 16.8 & & & \\
\hline \multirow[t]{3}{*}{ Ovotransferrin $(\mu \mathrm{g} / \mathrm{ml})$} & $\mathrm{L} 1+2$ & 13.2 & 10.8 & 14.1 & 0.34 & 0.761 & 0.031 & 0.226 \\
\hline & L1 & 17.8 & $11.1^{\mathrm{B}}$ & $22.1^{\mathrm{Ax}}$ & 4.59 & & & \\
\hline & $\mathrm{L} 2$ & 8.5 & 10.6 & $6.0^{\mathrm{y}}$ & 4.83 & & & \\
\hline \multirow[t]{3}{*}{ Alpha-1-acid glycoprotein $(\mu \mathrm{g} / \mathrm{ml})$} & $\mathrm{L} 1+2$ & 221.1 & 204.7 & 209.6 & 13.13 & 0.686 & 0.139 & 0.342 \\
\hline & L1 & 240.7 & 223.8 & 205.5 & 18.04 & & & \\
\hline & L2 & 201.5 & 185.7 & 213.8 & 18.99 & & & \\
\hline
\end{tabular}


FE, feed efficiency; L1 University of Veterinary Medicine Vienna (Vienna, Austria); L2, Agri-Food and Biosciences Institute (Hillsborough, Northern Ireland, UK).

${ }^{1}$ Values are least squares means \pm standard error of the mean (SEM).

${ }^{2}$ Each RFI group represents $n=9$ female chickens at location $1 ; n=6$ low RFI, $n=11$ medium RFI and $n=8$ high RFI females at location 2 . ${ }^{3} P$ : probability level.

${ }^{4}$ Linear polynominal contrast: $* P \leq 0.05, * * * P \leq 0.001$, and $\dagger P \leq 0.10$.

${ }^{\mathrm{a}-\mathrm{c}}$ Least squares means within a row without a common lowercase superscript differ among RFI groups $(P<0.05)$.

${ }^{\mathrm{A}, \mathrm{B}}$ Least squares means within a row without a common uppercase superscript tend to differ among RFI groups $(P<0.1)$.

${ }^{\mathrm{x}, \mathrm{y}}$ Least squares means within a column without a common lowercase superscript differ between locations $(P<0.05)$.

${ }^{\mathrm{X}, \mathrm{Y}}$ Least squares means within a column without a common uppercase superscript tend to differ between locations $(P<0.1)$. 
637 Table 4. Serum metabolites and acute-phase-proteins in male broiler chickens raised at two different locations.

\begin{tabular}{|c|c|c|c|c|c|c|c|c|}
\hline \multirow[b]{2}{*}{ Parameter } & \multirow[b]{2}{*}{ Location } & \multicolumn{3}{|c|}{ Residual feed intake ${ }^{1,2}$} & \multirow[b]{2}{*}{ SEM } & \multicolumn{3}{|c|}{$P$-value ${ }^{3,4}$} \\
\hline & & Low & Medium & High & & FE & location & $\mathrm{FE} \times$ location \\
\hline \multirow[t]{3}{*}{ Glucose (mg/dl) } & $\mathrm{L} 1+2$ & 295 & 312 & 317 & 15.9 & 0.585 & $<0.001$ & 0.377 \\
\hline & L1 & 270 & $257^{x}$ & $272^{\mathrm{x}}$ & 23.1 & & & \\
\hline & $\mathrm{L} 2$ & 320 & $368^{y}$ & $362^{y}$ & 21.8 & & & \\
\hline \multirow[t]{3}{*}{ Urea (mg/dl) } & $\mathrm{L} 1+2$ & 2.30 & 2.38 & 2.66 & 0.194 & 0.406 & 0.126 & 0.665 \\
\hline & $\mathrm{L} 1$ & 2.34 & 2.61 & 2.93 & 0.283 & & & \\
\hline & L2 & 2.27 & 2.16 & 2.40 & 0.267 & & & \\
\hline \multirow[t]{3}{*}{ Cholesterol (mg/dl) } & $\mathrm{L} 1+2$ & $134^{\mathrm{A}}$ & $142^{\mathrm{A}}$ & $157^{\mathrm{B}}$ & 5.2 & $0.010^{* *}$ & 0.133 & 0.453 \\
\hline & L1 & 143 & 142 & 162 & 7.5 & & & \\
\hline & $\mathrm{L} 2$ & $125^{\mathrm{a}}$ & $142^{\mathrm{ab}}$ & $153^{b}$ & 7.2 & & & \\
\hline \multirow[t]{3}{*}{ Triglycerides (mg/dl) } & $\mathrm{L} 1+2$ & $91^{\mathrm{B}}$ & 102 & $119^{\mathrm{A}}$ & 11.9 & $0.248 \dagger$ & 0.001 & 0.226 \\
\hline & L1 & 84 & $71^{x}$ & $86^{x}$ & 17.3 & & & \\
\hline & $\mathrm{L} 2$ & 98 & $133^{y}$ & $153^{y}$ & 16.3 & & & \\
\hline \multirow[t]{3}{*}{ NEFA $(\mu \mathrm{mol} / 1)$} & $\mathrm{L} 1+2$ & 253 & 295 & 293 & 25.9 & 0.429 & 0.354 & 0.126 \\
\hline & L1 & 244 & 318 & $238^{x}$ & 37.7 & & & \\
\hline & $\mathrm{L} 2$ & $262^{\mathrm{B}}$ & 273 & $348^{\mathrm{yA}}$ & 35.6 & & & \\
\hline \multirow[t]{3}{*}{ Ovotransferrin $(\mu \mathrm{g} / \mathrm{ml})$} & $\mathrm{L} 1+2$ & 7.61 & 11.86 & 13.24 & 3.06 & 0.394 & 0.743 & 0.904 \\
\hline & L1 & 7.79 & 11.71 & 14.96 & 4.22 & & & \\
\hline & $\mathrm{L} 2$ & 7.43 & 12.01 & 11.52 & 4.33 & & & \\
\hline \multirow[t]{3}{*}{ Alpha-1-acid glycoprotein $(\mu \mathrm{g} / \mathrm{ml})$} & $\mathrm{L} 1+2$ & 202.1 & 227.1 & 235.0 & 16.59 & 0.338 & 0.164 & 0.246 \\
\hline & L1 & $195.3^{\mathrm{b}}$ & $241.7^{\mathrm{ab}}$ & $267.9^{\mathrm{ax}}$ & 24.46 & & & \\
\hline & $\mathrm{L} 2$ & 208.8 & 212.5 & $202.1^{\mathrm{Y}}$ & 23.50 & & & \\
\hline
\end{tabular}


FE, feed efficiency; L1, University of Veterinary Medicine Vienna (Vienna, Austria); L2, Agri-Food and Biosciences Institute (Hillsborough, Northern Ireland, UK).

${ }^{1}$ Values are least squares means \pm standard error of the mean (SEM).

${ }^{2}$ Each RFI group represents $n=9$ male chickens at location $1 ; n=10$ low RFI, $n=9$ medium RFI, and $n=9$ high RFI males at location 2.

${ }^{3} P$ : probability level.

${ }^{4}$ Linear polynominal contrast contrast: $* * P \leq 0.01$, and $\uparrow P \leq 0.10$.

${ }^{\text {a-c } L e a s t ~ s q u a r e s ~ m e a n s ~ w i t h i n ~ a ~ r o w ~ w i t h o u t ~ a ~ c o m m o n ~ l o w e r c a s e ~ s u p e r s c r i p t ~ d i f f e r ~ a m o n g ~ R F I ~ g r o u p s ~}(P<0.05)$.

${ }_{\mathrm{A}, \mathrm{B}}$ Least squares means within a row without a common uppercase superscript tend to differ among RFI groups $(P<0.1)$.

${ }^{\mathrm{x}, \mathrm{y}}$ Least squares means within a column without a common lowercase superscript differ between locations $(P<0.05)$.

${ }^{\mathrm{X}, \mathrm{Y}}$ Least squares means within a column without a common uppercase superscript tend to differ between locations $(P<0.1)$. 
647

Table 5. White blood cells in female and male broiler chickens raised at location 1.

\begin{tabular}{|c|c|c|c|c|c|}
\hline \multirow[b]{2}{*}{ Parameter } & \multicolumn{3}{|c|}{ Residual feed intake ${ }^{1,2}$} & \multirow[b]{2}{*}{ SEM } & \multirow[b]{2}{*}{ FE, $P$-value ${ }^{3,4}$} \\
\hline & Low & Medium & High & & \\
\hline \multicolumn{6}{|l|}{ Females } \\
\hline Lymphocytes (\%) & 86.3 & 83.8 & 84.9 & 1.36 & 0.465 \\
\hline Heterophils (\%) & 12.1 & 13.4 & 13.2 & 1.25 & 0.730 \\
\hline Basophils (\%) & 0.07 & 0.17 & 0.03 & 0.05 & 0.160 \\
\hline Monocytes (\%) & 1.57 & 2.52 & 1.92 & 0.27 & 0.064 \\
\hline H-to-L proportion $(\%)$ & 14.2 & 16.3 & 15.8 & 1.76 & 0.680 \\
\hline \multicolumn{6}{|l|}{ Males } \\
\hline Lymphocytes (\%) & 83.6 & 82.6 & 75.3 & 2.14 & $0.023^{*}$ \\
\hline Heterophils (\%) & 13.9 & 15.0 & 20.6 & 2.06 & $0.067^{*}$ \\
\hline Basophils (\%) & 0.14 & 0.00 & 0.23 & 0.08 & 0.121 \\
\hline Monocytes (\%) & 2.37 & 2.32 & 2.81 & 0.39 & 0.629 \\
\hline H-to-L proportion $(\%)$ & 17.0 & 18.7 & 28.5 & 3.44 & $0.057 *$ \\
\hline
\end{tabular}

648 FE, feed efficiency; location 1, University of Veterinary Medicine Vienna (Vienna, Austria).

$649{ }^{1}$ Values are least squares means \pm standard error of the mean (SEM)

$650{ }^{2}$ Each RFI group represents $n=9$ chickens females and males.

$651{ }^{3} P$ : probability level.

$652{ }^{4}$ Linear polynominal contrast: $* P \leq 0.05 ; * * P \leq 0.01, * * * P \leq 0.001$, and $\dagger P \leq 0.10$.

${ }^{5}$ Nitrogen $\times 6.25$. 


\section{$654 \quad$ Figure captions}

655 Figure 1. a) Linear discriminant analysis of RFI groups and serum metabolites: low RFI 656 group $(\bigcirc)$, medium RFI group $(\diamond)$, and high RFI group $(\bullet)$. b) Linear discriminant analysis 657 of location and serum metabolites: location 1 (Austria $(\bigcirc)$ ), and location $2(\mathrm{UK}(\bigcirc)$ ). Circles 658 indicate $95 \%$ confidence intervals.

659

660 Figure 2. Quantification of relationships between RFI values and serum metabolites in male 661 and female chickens from both locations (A-C). Relation between chicken's RFI value (x) and 662 serum concentration (y) of cholesterol (A) and serum uric acid (B): linear regression, A) y= $663140.72+0.039 \times x, \mathrm{RMSE}=20.652, R^{2}=0.13, P<0.001$ and B) $y=2.34+0.00070 \times x$, root 664 mean square error $(\mathrm{RMSE})=0.143, R^{2}=0.49, P<0.001$. Relation between RFI value (x) and 665 blood heterophil-to-lymphocyte proportion in chickens at location 1 (C): linear regression, $y=$ $66617.98+0.018 \times x, \mathrm{RMSE}=8.358, R^{2}=0.15, P=0.003$. 


\section{Metzler-Zebeli et al. - Supplemental Material}

2 Supplemental Table 1. Ingredients and chemical composition of diets.

\begin{tabular}{|c|c|c|c|}
\hline Item & Starter $^{1}$ & Grower $^{2}$ & Finisher $^{3}$ \\
\hline \multicolumn{4}{|l|}{ Ingredient (g/kg as-fed) } \\
\hline Corn & 612 & 660 & 679 \\
\hline Soybean meal & 331 & 282 & 260 \\
\hline Soybean oil & 17.5 & 20.6 & 27.7 \\
\hline Limestone flour & 11.0 & 9.8 & 7.0 \\
\hline Salt & 2.0 & 2.0 & 2.3 \\
\hline Dicalcium phosphate & 16.1 & 15.0 & 13.4 \\
\hline Vitamin/mineral-premix & 11.0 & 11.0 & 10.0 \\
\hline \multicolumn{4}{|c|}{ Analyzed chemical composition (g/kg DM) at L1 } \\
\hline Dry matter & 926 & 923 & 914 \\
\hline Crude protein & 243 & 223 & 216 \\
\hline Ether extracts & 50 & 52 & 59 \\
\hline Crude fiber & 31 & 27 & 28 \\
\hline Crude ash & 69 & 62 & 55 \\
\hline Starch & 462 & 506 & 514 \\
\hline Sugar & 40 & 46 & 49 \\
\hline Calcium & 11.9 & 10.7 & 8.9 \\
\hline Phosphorus & 8.2 & 7.8 & 6.9 \\
\hline \multicolumn{4}{|c|}{ Analyzed chemical composition (g/kg DM) at L2 } \\
\hline Dry matter & 908 & 902 & 902 \\
\hline Crude protein & 221 & 219 & 209 \\
\hline Crude ash & 94 & 81 & 72 \\
\hline Metabolizable energy $(\mathrm{MJ} / \mathrm{kg})$ & 13.7 & 14.3 & 14.6 \\
\hline
\end{tabular}

3

${ }^{1}$ Premix provided per kilogram of starter diet: vitamin A as retinyl acetate, 13,000 IU; vitamin $\mathrm{D}_{3}$ as cholecalciferol, 5,000 IU; vitamin E as alpha-tocopherol-acetate, $80 \mathrm{IU}$; vitamin $\mathrm{K}, 3 \mathrm{mg}$; thiamin, $3 \mathrm{mg}$; riboflavin, $9 \mathrm{mg}$; pyridoxine, $4 \mathrm{mg}$; vitamin $\mathrm{B}_{12,} 20 \mu \mathrm{g}$; biotin, $0.15 \mathrm{mg}$; calcium pantothenate, $15 \mathrm{mg}$; nicotinic acid, $60 \mathrm{mg}$; folic acid, $2 \mathrm{mg}$; $500 \mathrm{mg}$ choline chloride; methionine, 3,405 mg; threonine, $745 \mathrm{mg}$; lysine, 2,812 $\mathrm{mg}$; $\mathrm{I}, 1 \mathrm{mg}$ as calcium iodate; $\mathrm{Se}, 0.35 \mathrm{mg}$ as sodium selenite; Fe, $40 \mathrm{mg}$ as ferrous sulphate; Mo, $0.5 \mathrm{mg}$ as sodium molybdate; $\mathrm{Mn}, 100 \mathrm{mg}$ as manganous oxide; $\mathrm{Cu}, 15 \mathrm{mg}$ as copper sulfate; $\mathrm{Zn}, 100 \mathrm{mg}$ as zinc oxide. ${ }^{2}$ Premix provided per kilogram of grower diet: vitamin A as retinyl acetate, 10,000 IU; vitamin $\mathrm{D}_{3}$ as cholecalciferol, 5,000 IU; vitamin E as alpha-tocopherol-acetate, $50 \mathrm{IU}$; vitamin $\mathrm{K}, 3 \mathrm{mg}$; thiamin, $2 \mathrm{mg}$; riboflavin, $8 \mathrm{mg}$; pyridoxine, $3 \mathrm{mg}$; vitamin $\mathrm{B}_{12}, 15 \mu \mathrm{g}$; biotin, $0.12 \mathrm{mg}$; calcium pantothenate, $12 \mathrm{mg}$; nicotinic acid, $50 \mathrm{mg}$; folic acid, $2 \mathrm{mg}$; $400 \mathrm{mg}$ choline chloride; methionine, 3,018 mg; threonine, $726 \mathrm{mg}$; lysine, 2,831 $\mathrm{mg}$; $\mathrm{I}, 1 \mathrm{mg}$ as calcium iodate; $\mathrm{Se}, 0.35 \mathrm{mg}$ as sodium selenite; Fe, $40 \mathrm{mg}$ as ferrous sulphate; Mo, $0.5 \mathrm{mg}$ as sodium molybdate; $\mathrm{Mn}, 100 \mathrm{mg}$ as manganous oxide; $\mathrm{Cu}, 15 \mathrm{mg}$ as copper sulfate; $\mathrm{Zn}, 100 \mathrm{mg}$ as zinc oxide. ${ }^{3}$ Premix provided per kilogram of finisher diet: vitamin $\mathrm{A}$ as retinyl acetate, 10,000 IU; vitamin $\mathrm{D}_{3}$ as cholecalciferol, 5,000 IU; vitamin E as alpha-tocopherol-acetate, $50 \mathrm{IU}$; vitamin $\mathrm{K}, 3 \mathrm{mg}$; thiamin, $2 \mathrm{mg}$; riboflavin, $6 \mathrm{mg}$; pyridoxine, $3 \mathrm{mg}$; vitamin $\mathrm{B}_{12}, 15 \mu \mathrm{g}$; biotin, $0.12 \mathrm{mg}$; calcium pantothenate, $10 \mathrm{mg}$; nicotinic acid, $50 \mathrm{mg}$; folic acid, $1 \mathrm{mg} ; 350 \mathrm{mg}$ choline chloride; methionine, 2,514 mg; threonine, $361 \mathrm{mg}$; lysine, 1,779 

sodium molybdate; $\mathrm{Mn}, 100 \mathrm{mg}$ as manganous oxide; $\mathrm{Cu}, 15 \mathrm{mg}$ as copper sulfate; $\mathrm{Zn}, 100 \mathrm{mg}$ as zinc oxide.

$21{ }^{4}$ Calculated according to NRC (1994). 
23 Supplemental Table 2. Body weight, feed intake and growth performance between $\mathrm{d} 7$ and 21 of life of female and male broiler chickens raised at

24 two different locations.

\begin{tabular}{|c|c|c|c|c|c|c|c|c|}
\hline \multirow[b]{2}{*}{ Item } & \multirow[b]{2}{*}{ Location } & \multicolumn{3}{|c|}{ Residual feed intake ${ }^{1,2}$} & \multirow[b]{2}{*}{ SEM } & \multicolumn{3}{|c|}{$P^{3,4}$} \\
\hline & & Low & Medium & High & & $\mathrm{FE}$ & location & $\mathrm{FE} \times$ location \\
\hline \multicolumn{9}{|l|}{ Females } \\
\hline \multirow[t]{3}{*}{ Body weight, d 7 of life (g) } & $\mathrm{L} 1+2$ & 145 & 145 & 147 & 2.6 & 0.805 & 0.001 & 0.802 \\
\hline & L1 & 141 & $138^{\mathrm{y}}$ & 141 & 3.6 & & & \\
\hline & $\mathrm{L} 2$ & 149 & $151^{\mathrm{x}}$ & $153^{\mathrm{x}}$ & 2.6 & & & \\
\hline \multirow[t]{3}{*}{ Body weight, d 21 of life (g) } & $\mathrm{L} 1+2$ & 906 & 848 & 893 & 21.56 & 0.133 & $<0.001$ & 0.817 \\
\hline & L1 & $972^{\mathrm{x}}$ & $895^{\mathrm{x}}$ & $852^{x}$ & 29.48 & & & \\
\hline & $\mathrm{L} 2$ & $840^{\mathrm{y}}$ & $801^{\mathrm{y}}$ & $834^{y}$ & 31.35 & & & \\
\hline \multirow[t]{3}{*}{ Total feed intake, $\mathrm{d}$ 7-21 of life (g) } & $\mathrm{L} 1+2$ & $1009^{b}$ & $1023^{\mathrm{abB}}$ & $1083^{\mathrm{aA}}$ & 23.07 & $0.067^{*}$ & 0.339 & 0.391 \\
\hline & L1 & $1001^{\mathrm{b}}$ & $1059^{\mathrm{ab}}$ & $1094^{\mathrm{a}}$ & 31.55 & & & \\
\hline & $\mathrm{L} 2$ & 1017 & $987^{\mathrm{B}}$ & $1073^{\mathrm{A}}$ & 33.55 & & & \\
\hline \multirow[t]{3}{*}{ Total body weight gain, d 7-21 of life (g) } & $\mathrm{L} 1+2$ & 761 & 703 & 746 & 21.02 & 0.131 & $<0.001$ & 0.845 \\
\hline & L1 & $831^{x}$ & $757^{x}$ & $811^{\mathrm{x}}$ & 28.75 & & & \\
\hline & $\mathrm{L} 2$ & $691^{\mathrm{y}}$ & $650^{\mathrm{y}}$ & $681^{\mathrm{y}}$ & 30.57 & & & \\
\hline \multicolumn{9}{|l|}{ Males } \\
\hline \multirow[t]{3}{*}{ Body weight, d 7 of life (g) } & $\mathrm{L} 1+2$ & 145 & 145 & 148 & 2.173 & 0.704 & $<0.001$ & 0.919 \\
\hline & L1 & $139^{x}$ & $140^{\mathrm{x}}$ & $141^{\mathrm{x}}$ & 3.010 & & & \\
\hline & $\mathrm{L} 2$ & $152^{y}$ & $150^{\mathrm{y}}$ & $154^{y}$ & 3.047 & & & \\
\hline Body weight, d 21 of life (g) & $\mathrm{L} 1+2$ & 920 & 928 & 933 & 19.09 & 0.895 & $<0.001$ & 0.046 \\
\hline
\end{tabular}




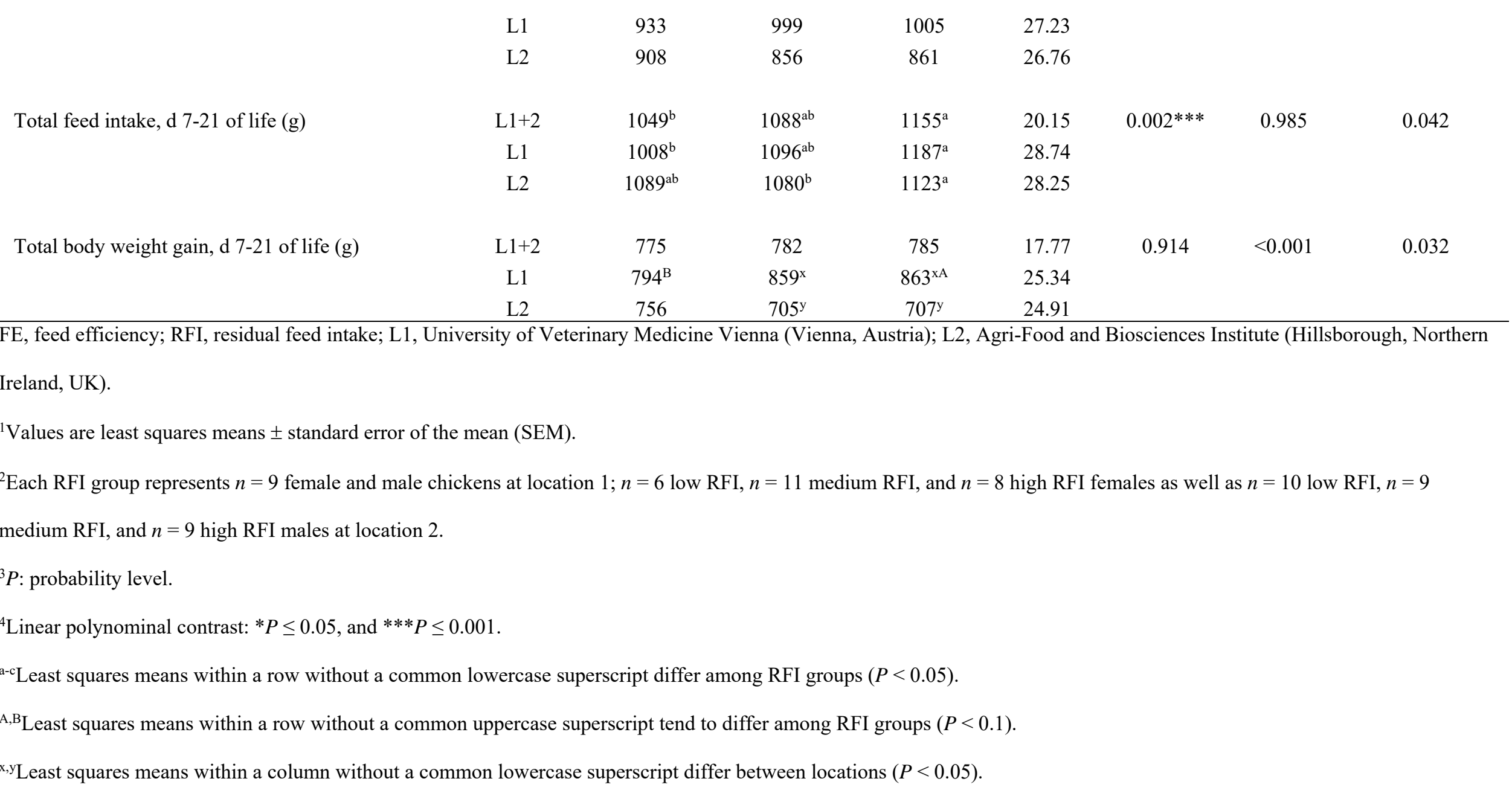


50

\section{Metzler-Zebeli et al. - Supplemental Material}

\section{Relationship analysis}

Single nucleotide polymorphism genotypes were used to examine the genetic relationship of all birds within and between each population received. In order to achieve the genetic relationship of each pair of samples supplied, a G-matrix was established using the PreGS program by Prof I. Misztal (Animal Breeding and Genetics group, University of Georgia, Athens, GA, USA). Supplemental Table 2 lists the relationship statistic per population. These data indicate that there is very little genetic relationship between any two birds within replicate batch 1 and replicate batch 2 from the location 1 . In replicate batch 3 at location 1, two birds appeared to be half-sibs (relationship of 0.25 ). Similarly, the replicate batch 1 from location 2 appeared to contain two birds that are half-sibs (relationship of 0.20 ). The overall relationships within and between populations has been plotted and is illustrated in Supplemental Figure 1.

Supplemental Table 3. Genomic relationships among chickens.

\begin{tabular}{lcccccc}
\hline \multicolumn{9}{c}{ genomic } \\
comparisons & $\begin{array}{c}\text { relationships } \\
\text { among birds }\end{array}$ & & & \\
Location $1+2$ & 2415 & mean & sd & min & max \\
\hline
\end{tabular}

Supplemental Figure 1. G-relationships among chickens from both locations.

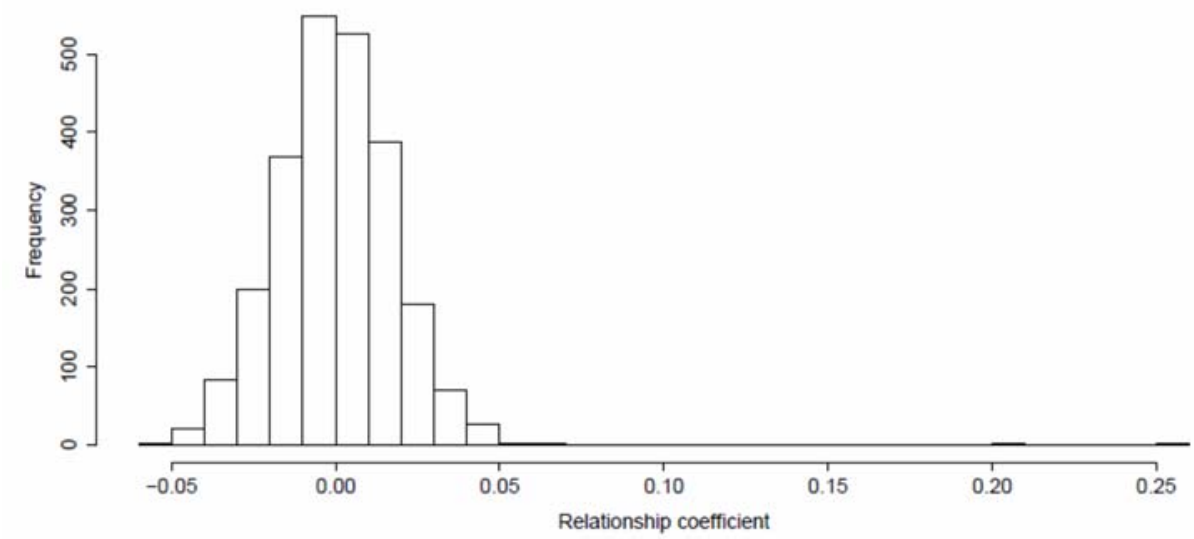




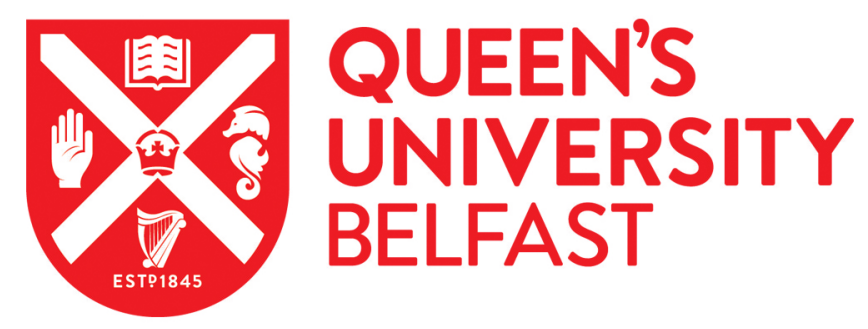

\section{Assessing serum metabolite profiles as predictors for feed efficiency in broiler chickens reared at geographically distant locations}

Metzler-Zebeli, B., Magowan, E., Hollman, M., Ball, E., Molnar, A., Lawlor, P. G., ... Zebeli, Q. (2017). Assessing serum metabolite profiles as predictors for feed efficiency in broiler chickens reared at geographically distant locations. BRITISH POULTRY SCIENCE, 1-10. DOI: 10.1080/00071668.2017.1362688

Published in:

BRITISH POULTRY SCIENCE

Queen's University Belfast - Research Portal:

Link to publication record in Queen's University Belfast Research Portal

\section{General rights}

Copyright for the publications made accessible via the Queen's University Belfast Research Portal is retained by the author(s) and / or other copyright owners and it is a condition of accessing these publications that users recognise and abide by the legal requirements associated with these rights.

Take down policy

The Research Portal is Queen's institutional repository that provides access to Queen's research output. Every effort has been made to ensure that content in the Research Portal does not infringe any person's rights, or applicable UK laws. If you discover content in the Research Portal that you believe breaches copyright or violates any law, please contact openaccess@qub.ac.uk. 

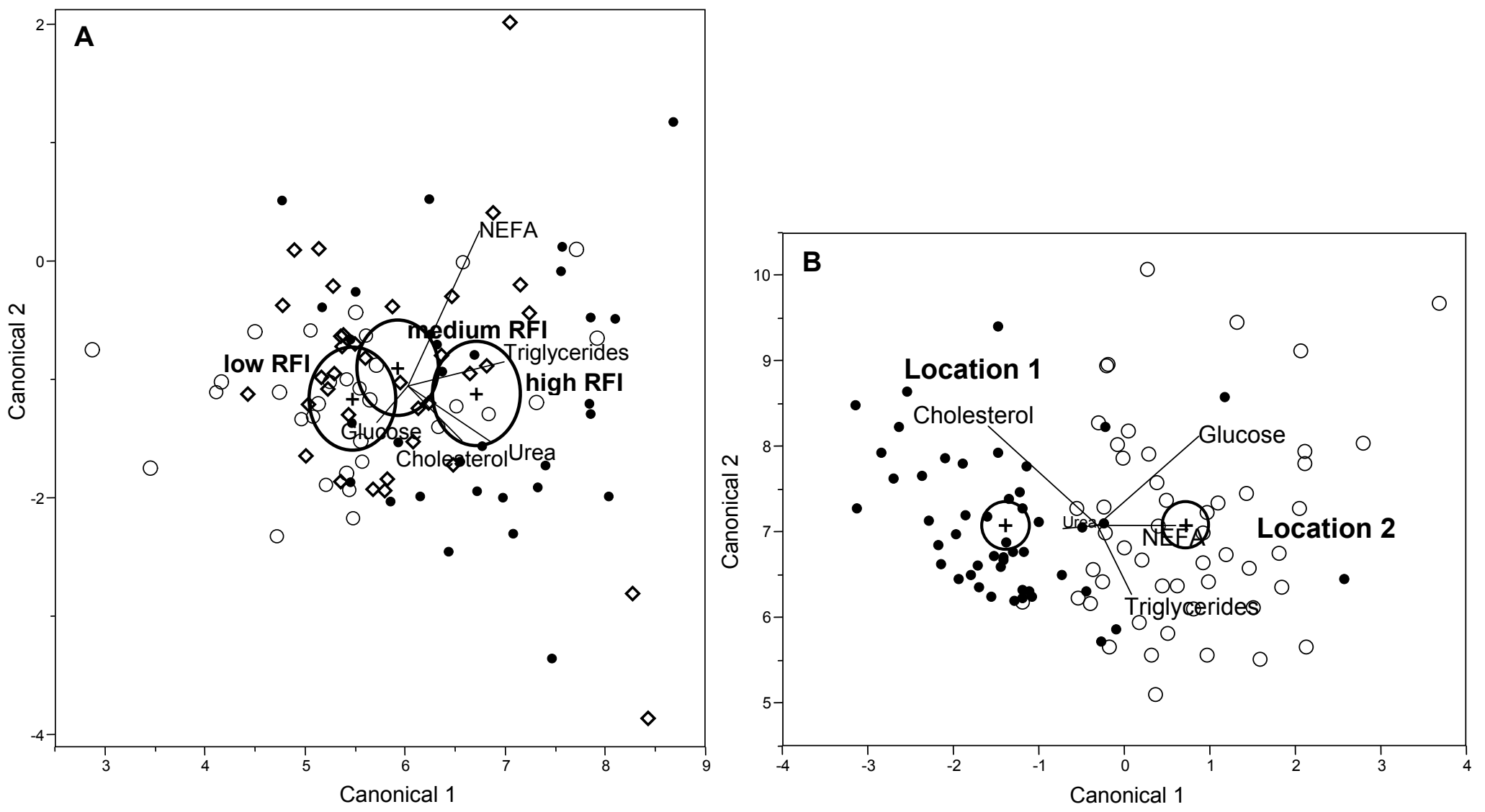

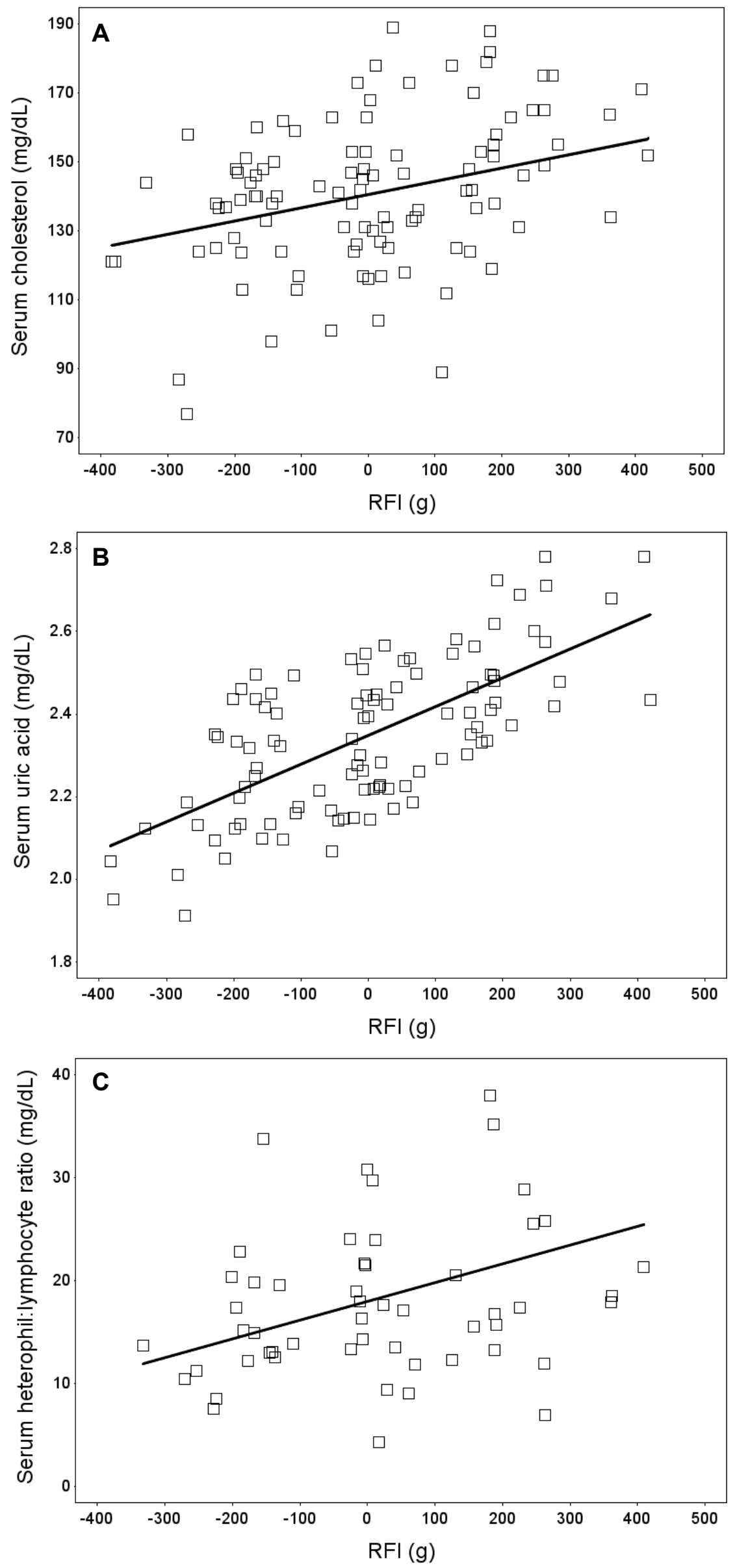